\title{
What is Engagement and How Do We Measure It? Toward a Domain Independent Definition and Scale
}

\author{
Triparna de Vreede, Stephanie Andel, Gert-Jan de Vreede, Paul Spector, Vivek Singh, Balaji Padmanabhan \\ University of South Florida \\ $\{$ tdevreede, sandel, gdevreede, pspector, vivek4, bp\}@usf.edu
}

\begin{abstract}
An engaging experience draws in and holds our attention. Engagement is a critical phenomenon of interest in a variety of disciplines and application domains and has been shown to lead to positive outcomes, such as enhanced learning, task performance, or job satisfaction. However, existing measures of engagement are typically specific to the domain in which the research is conducted. This paper builds on the synergies of various disciplines and proposes a discipline-independent definition of engagement and measurement scale. In this paper, we distinguished between the three temporal levels of engagement in terms of the expected length of the engagement (task/activity, initiative, and continuous). We further explored the differences in the conceptualization of engagement, viz. affective, behavioral, and cognitive engagement. We then offered a comprehensive definition of engagement. We finally developed a measurement scale that can be used across domains and contexts which we derived by iteratively refining the items in this scale through a series of five data samples to arrive at the final scale. Our results provide evidence for the scale's validity in two domains (online learning and work engagement).
\end{abstract}

\section{Introduction}

Engagement has emerged as an important psychological concept that impacts human behavior and choice across many domains including education, employment, leisure, and marketing. For example, the digital evolution in the past decades has transformed the nature of human computer interaction (HCI), shifting it from simpler user interfaces to interactive and engaging experiences [53]. An engaging experience is one that can draw us in and hold our attention [6]. Engagement for users means more in today's environment than just a satisfying experience. The explosion of interest in gaming ${ }^{1}$, for instance, is in part due to how engaging these games are being made for users. The proliferation of web-based platforms and apps has resulted in users having multiple options that offer the content of their

${ }^{1}$ https://uxdesign.cc/how-video-games-trigger-extreme-userengagement-2b773f107b29 choice. Interfaces that fail to engage users sufficiently are at a disadvantage in such an environment. The hallmark of successful technologies now has an extra requirement of engagement in addition to usefulness and usability. In other words, the very survival of technology-based platforms may be dependent on the degree of engagement they can elicit from their users and the speed with which this engagement is built.

This importance of engagement is reflected across multiple disciplines. Even though the contexts differ, they all appear to reveal a similar pattern: engagement in the material or task at hand leads to positive outcomes for the user. For instance, education researchers have created an extensive literature concerning factors that enable students to be more engaged in their scholastic pursuits $[7,59]$. Similarly, organizational psychology is heavily invested in workplace engagement and observing its effects on factors like employee performance, productivity, and satisfaction [3]. Multiple engagement studies can also be found in the ecommerce literature $[39,57]$ where some of the phenomena studied include the purchase of products, or willingness to persist in browsing a website.

Despite the wealth of research on user engagement and the relevance of these findings across domains, the studies are siloed and reported within their own disciplines, and thus are less familiar to those outside it. This separation impedes progress in engagement research as researchers may not know that they can build upon previous research that has been conducted in other domains. This hampers our efforts to understand this concept to the advantage of the users and organizations alike. The disconnect between disciplines has also led to other issues like inconsistent definitions of engagement $[16,22]$. Many measures of engagement, while robust, are so specific to the domains where they are developed, that they cannot easily be transferred or generalized to other contexts. Consequently, other domains are not able to effectively take advantage of these measures in their own research.

In summary, despite the cross-domain acknowledgement of engagement as an important phenomenon of interest, there have been insufficient efforts to create a bridge that allows researchers across 
disciplines who study various domains to utilize all available resources to advance this field of research. Our vision is to enable researchers to capitalize on the synergies of various disciplines and seamlessly build upon each other's work. However, the journey of a thousand miles begins with a single step - in this case, the first step is to find a definition of engagement that can be relevant across most domains and to create a measure of engagement that can be used to assess the levels of engagement in a manner that supports the above said definition across disciplines. Currently, to our knowledge, there are no established scales that can reliably measure the engagement construct across disciplines. To establish such a scale, it is important to define engagement and identify its measurable and identifiable components that remain stable irrespective of the context where it is measured.

Consequently, the purpose of this paper is twofold. First, we develop a discipline independent definition of engagement. Second, we develop a reliable disciplineindependent scale and provide preliminary evidence to support its validity in two domains (i.e., online learning and work engagement). Our long-term goal is to extend this work to other domains of engagement. The remainder of the paper is structured as follows: in the next section, we provide an overview of the engagement literature from several disciplines that were reviewed and analyzed to create a domain independent definition of engagement and a domain adaptable engagement scale. These disciplines include e-commerce, marketing, organizational behavior, education, crowdsourcing, and HCI. In the subsequent section, we elaborate on the process of engagement scale development over five samples. We then present our findings in the results section, discuss their implications and end with a description of the limitations and future directions.

\section{Current Definitions and Contributions}

\subsection{Temporal and contextual classification of engagement}

In its relatively short (approx. 35 year) history, engagement has proven itself to be a multidimensional and multidisciplinary phenomenon that is addressed from three temporal levels. That is, engagement can be viewed in terms of being a short term, medium term, or a long-term phenomenon. This length of time can range from minutes to days, to a lifetime of the relationship.

Task/activity duration: In many instances, engagement is viewed as a limited time phenomenon. That is, the engagement of a person is measured during the duration of the activity. This fixed task/activity duration conceptualization of engagement is relevant in online and gaming environments, for instance, where the object of interest is the individual's engagement only while they are performing the activity. Also, engagement in Internet-based platforms involve playfulness, sensory integration, first impressions of the platform, and enjoyment that users experience [31, 43]. Similarly, in e-commerce engagement is viewed through the lens of user actions and behaviors while they are in the website, app, or portal. In addition, in education, researchers are often interested in the engagement of students in online courses during a learning session such as watching a lecture video or completing an assignment.

Initiative duration. On other occasions, engagement is viewed as a moderately persistent phenomenon that is measured across the lifetime of a certain project or initiative. For example, in community crowdsourcing, engagement involves the persistence of making contributions and the extent of these contributions over a specific period. In other words, while these contributions are not a one-time event, they do carry an expiry date. Similarly, in education, engagement may be viewed to be something that persists across a semester-long course or a full program. Workplace engagement also addresses the mediumterm aspect of engagement by assessing employee engagement in specific projects.

Continuous engagement. Finally, engagement can be viewed as a long term and abstract phenomenon. From this perspective, engagement is an ongoing condition or state of being that lasts as long as the relationships between the entities last. For instance, in organizational psychology, engagement is thought of as a motivational concept referring to "the simultaneous employment and expression of a person's 'preferred self' in task behaviors that promote connections to work and to others, personal presence (physical, cognitive, and emotional) and active, full performances" [26, p.700]. Engaged employees are often described as fully present psychologically; in addition, they are described as attentive, connected, integrated, and focused on performing their role [45]. The long-term view of engagement can also be seen in the education literature. For example, some researchers have defined engaged students as ones who are involved with school, have a sense of belonging, and accept the goals of schooling [13]. Another instance where a long-term perspective is utilized concerns community engagement. In community engagement, citizens contribute to solving the challenges of their community with each topic/issue for an extended period of time. Finally, even in domains that are interested in short term engagement, like sales and marketing, engagement is sometimes viewed as a "an intimate long-term relationship with the customer" [11].

Attributes of engagement can also be derived according to the context in which engagement is measured. In some cases, success of the initiative 
depends on actual contributions and active involvement of the user - like e-commerce, online gaming, and crowdsourcing. In such cases, the characteristics of engagement have been identified as the degree and quality of participation [1]. Similarly, in marketing and sales, customer engagement has been measured through exchange-relationship dimensions ranging from short term to long term and from cursory to intimate [50].

In other cases, engagement towards the initiative is more abstract, like engagement towards education or work in general. In such cases, the characteristics of engagement are less specific to events and more focused on the state of mind and attitude towards the situation [8]. Some other contexts for engagement include viewing engagement as an experience and evaluating the attitude of the participants towards that experience [5]. In such cases, engagement is often viewed more from an emotional perspective rather than an intellectual one. In short, definitions of degree and quality are often context dependent on the domain and all perspectives need to be examined to arrive at a definition that can be relevant across contexts and domains.

\subsection{Definitions of engagement}

Depending on the context and the temporal classifications, different definitions in the literature were developed to highlight the various relevant attributes of engagement. For example, one definition attributes engagement to a "positive fulfilling work related state of mind that is characterized by vigor, dedication and absorption" [51, p. 702]. Another describes engagement as “one's psychological presence in or focus on role activities and may be an important ingredient for effective role performance" [47, p. 656]. Engagement has been attributed to resultant outcomes and attitudes towards oneself as in the definition that describes it as "an energetic state of involvement, personally fulfilling activities that enhance one's sense of personal efficacy" [37, p. 498]. Some other definitions describe engagement as a satiation of psychological needs (i.e., autonomy, belonging, competence) within cultural enterprises such as family, school, and work [8]. This definition also includes the manifestation of engagement in the form of affect, behavior, and cognition.

Another interesting take on engagement was presented by Macey and Schneider [34], who organized engagement into three separate but interrelated categories: trait engagement, state engagement, and behavioral engagement. They defined trait engagement as "the inclination or orientation to experience the world from a particular vantage point (e.g., positive affectivity characterized by feelings of enthusiasm)" (p. 5). They conceptualized state engagement "as an antecedent of behavioral engagement (e.g., feelings of energy, absorption)" (p. 6). Finally, they defined behavioral engagement "in terms of discretionary effort or a specific form of in-role or extra-role effort or behavior" (p.6). Macey and Schneider [34] argue that trait engagement gets reflected in psychological state engagement, which in turn shows up in the form of discretionary effort.

Yet, other researchers define engagement in terms of satisfaction with experience. For example, Calder, Malthouse, and Schaedel [5] argue that users are engaged when their experience with a website fits into their expectations of what that site should provide. Such expectations can range from being utilitarian to inspiring to relaxing among other things. Finally, Kahn [26] proposed another definition for engagement in workplace literature. He described engagement as how people can "use varying degrees of their selves, physically, cognitively, and emotionally in work role performances" [26, p. 692].

\subsection{Common Conceptual Components of Engagement}

It can be observed from the analysis of the engagement studies from various domains, that a pattern of constructs that emerges across the conceptualizations of engagement. The components that repeat across domains and contexts are affect, cognition, and behavior. In the early phases of engagement research, a twocomponent theory of engagement consisting of behavioral (e.g., positive conduct, effort, participation) and emotional or affective subtypes (e.g., interest, identification, belonging, positive attitude about learning) was commonly used, with both subtypes foundational to understanding engagement [12, 36, 41, 58]. Shortly, an additional component of cognition (e.g., self-regulation, learning goals, and investment in learning) was added to the two-component theory of engagement, resulting in a tripartite conceptualization [15, 25]. Currently, most researchers seem to converge on the three-faceted theory of engagement [10, 26, 34, 45, 48]. Therefore, we are persuaded that any definition of engagement should encompass all three components, viz. affect/emotion, behavior, and cognition (ABCs of engagement). Each of these components is elaborated below.

Affect/Emotion: Researchers use terms like satisfaction, emotion, positive state of mind, and enthusiasm to describe the state of engagement [30, 34, 48, 49, 33]. For instance, organizations like Gallup equate engagement with an "individual's involvement and satisfaction with as well as enthusiasm for work" [21, p. 269]. Researchers such as May, Gilson, and Harter [38] operationalize emotional engagement as an emotional attachment to the workplace experience. Within the academic space, researchers measure the 
emotional dimension of engagement in terms of positive affective reactions to the academic experience, including emotions such as happy, interested, and excited. Researchers of academic engagement have often measured this construct as the degree of belongingness felt towards the school [14].

Given the various perspectives of emotional engagement, it is no surprise that the definitions of emotional engagement also vary across the literature. For example, workplace engagement is defined as "a positive, fulfilling, work-related state of mind that is characterized by vigor, dedication, and absorption" [ $[52$, p.74]. Another definition states that emotional engagement "revolves around the emotional bond one feels toward his or her place of work" [54, p. 423]. Yet another definition states that employees who are emotionally engaged display "a sense of belonging and identification that increases . . . involvement in the organization's activities" [44, p. 825].

These definitions of emotional engagement influenced the creation of emotional engagement scales. For instance, engagement has been measured with items like "I am interested in the work at my school" [17], "I feel proud of being a part of my school" [12], "My own feelings are affected by how well I perform my job" [38] or "I am enthusiastic in my job" [45]. Further, other researchers focus upon emotional disengagement, measured as the extent of negative emotions that result from the task (e.g., "When we work on something in class, I feel discouraged") [55]. Other researchers have measured emotional engagement towards a specific task or activity with a limited temporal scope. For example, items like "The game was lots of fun" [24].

It appears that the literature mostly focuses on measuring emotional engagement from the perspective of positive emotions generated by the phenomenon of interest. However, some studies also measure emotional engagement as a fleeting phenomenon. Since engagement can be a generalized experience or it can be specific to a certain task or activity, we define emotional engagement as the extent to which individuals experience a positive psychological reaction or attachment towards a specific activity, initiative, or situation.

Behavior: Behavioral engagement is associated by researchers with acts of discretionary effort and has been represented by terms such as participation, task involvement, and prosocial conduct [15]. It has also been associated with words like proactive behavior [56]. Other researchers conceptualize behavioral engagement as basic compliance with a task, and examine things such as participation, concentration, effort, and adherence to rules and instructions [16].

Behavioral engagement has also been assessed within the various engagement literatures. For instance, items such as "I pay attention in class" [17] and "When
I'm in class, I listen very carefully" [55] are commonplace within the academic literature. Within the marketing domain, customer engagement is described as a customer's behavioral manifestation of motivation toward a specific brand or product [57], while organizational psychology considers behavioral engagement to be the discretionary and externally manifested effort exerted toward one's job tasks [34]. Further, some researchers across disciplines focus on behavioral disengagement, such as pretending to work or not actually completing tasks (e.g., "When I'm in class, I just act like I'm working") [55].

Behavioral engagement is often defined in the literature as observable actions, such as "student conformity to classroom and school rules" [2]. Griffin, Parker, and Neal [20] define behavioral engagement as "'going beyond' standard or typical expectations (of behavior)" (p. 3). It is also defined in terms of observations: "Behavioral engagement can be observed when students contribute to classroom discussion, attend to an academic task, and demonstrate they are listening to teacher instruction" [19, p. 21]. Finally, some researchers have narrowed the definition of behavioral engagement to just the behaviors that can be explicitly observed and have defined behavioral engagement to be the action where in participants exert more effort, persist longer at tasks, and actively seek help [42]. For example, Linnenbrink and Pintrich [32] assessed the behavioral engagement of students by observing how long students persisted at a task or how much help they sought from teachers when they were stuck.

Given the literature that defines behavioral engagement both in terms of specific instances as well as more generalized situations, we propose a definition of behavioral engagement that can be applicable to both types of phenomena. Thus, we define behavioral engagement as the extent to which the individuals can be observed to exert effort and show persistence to remain involved in an activity or situation.

Cognition: Some researchers refer to engagement as a cognition or a state of intellectual effort. Terms such as intellectual commitment, or cognition have been used in the literature to describe engagement. As mentioned earlier, employee engagement is viewed as a manifestation of the cognitive judgment of the ability of the job or task to satisfy the individual's need vis-a vis that task [27, 34, 47, 49]. It also refers to the use of cognitive strategies to complete a task, to self-regulate, and to perform the basic requirements and beyond for the task [16]. Others refer to cognitive engagement as complete absorption and focus on a task $[9,38]$. Some researchers evaluate cognitive engagement in terms of processing, arguing that deeper engagement results in deeper processing of information [18]. Cognitive engagement has also been equated with being "involved 
with the information presented [and] really thinking about it (analyzing, synthesizing, evaluating), rather than just passively receiving it" [28, p. 2].

Definitions of cognitive engagement show evidence of these perspectives. Some examples include: Rotgans and Schmidt [46] define engagement as a "psychological state in which students put in a lot of effort to truly understand a topic and in which students persist studying over a long period of time." (p. 465). Others defined it as a "relatively stable cognitive state where an employee is psychologically present and focused on the job and its related activities" [23, p.12]. Greene [18] defined it as "involving the active use of prior knowledge and the intentional creation of more complex knowledge structures by integrating the new information with prior knowledge".

As with affective and behavioral engagement, definitions of cognitive engagement influenced the creation of measurement scales. For instance, the School Engagement Measure assesses cognitive engagement as the use of cognitive strategies with items such as, "When I read a book, I ask myself questions to make sure I understand what it is about" [17]. Others measure cognitive engagement from an absorption and focus perspective (e.g., May, Gilson, \& Harter, 2004; "Performing my job is so absorbing that I forgot about everything else") [38], which is what others might consider as "flow" [9]. However, some evaluate cognitive engagement in terms of going beyond the requirements of a task.

Despite some deviations, it appears that cognitive engagement is predominantly considered in the literature to be the extent to which an activity captures an individual's full attention and most of their cognitive resources. In other words, when people are cognitively engaged with a task, they are only vaguely aware of their surroundings and cannot recall the exact nature of the goings on at a later point [9]. Consequently, we define cognitive engagement as the extent to which individuals are intellectually absorbed in a task or activity resulting in a reduced awareness of their surroundings.

As can be observed in the literature and the proposed definitions, engagement is a three-factor concept. Yet, it appears that not all factors need be present in an engaged individual. An individual who is behaviorally engaged may not be cognitively or emotionally engaged or vice versa. For instance, someone who is watching a movie may be emotionally and behaviorally engaged, but not cognitively so. Similarly, someone who is productively putting stamps on an envelope maybe behaviorally engaged, but not be engaged cognitively or emotionally. A student may be behaviorally engaged in terms of keeping the gaze focused on the teacher or the screen, but may not be cognitively engaged towards the material being taught.
This distinction is important for engagement researchers to understand. Thus, it is not only critical to understand and measure different types of engagement, but it is also necessary to keep these constructs conceptually separate from each other and not combine them into a single definition and measure. Accordingly, we propose that engagement is a three-part phenomenon, which manifests in one or more of the following three forms:

1. Affective/Emotional engagement: the extent to which individuals experience a positive psychological reaction or attachment towards a specific activity or situation.

2. Behavioral engagement: the extent to which the individuals can be observed to exert effort and show persistence to remain involved in an activity or situation.

3. Cognitive engagement: the extent to which individuals are cognitively absorbed in a task or activity resulting in a reduced awareness of their surroundings.

These three aspects of engagement form the basis for the engagement scale we propose in this paper. This instrument covers all essential aspects of engagement and is non-aggregate in nature between the aspects to accommodate for any activity with varying temporal and contextual characteristics. This comprehensive and yet compartmentalized approach to engagement is intended to render this instrument valid in a broad array of contexts and environments.

\section{Method}

Scale development requires a specific series of steps in order to construct a reliable and valid scale. Specifically, as outlined by MacKenzie, Podsakoff, and Podsakoff [35], proper scale development requires the following ten steps: 1) form a conceptual definition of the construct, 2) generate items, 3) assess content validity, 4) specify the measurement model, 5) collect data to pre-test, 6) scale refinement, 7) gather new sample and re-examine scale properties, 8) assess scale validity (repeat 6-8 as needed), 9) cross-validate the scale with samples from different populations, and 10) develop scale norms. This paper reports on the first eight steps of this process. The conceptual definitions (Step 1) can be found in the background of this submission.

After creating the conceptual definitions (Step 1) and reviewing the literature, a series of items were generated by the researchers to measure each subdimension of engagement (Step 2). In the first iteration, emotional and cognitive engagement sub-dimensions had six items each and behavioral engagement had seven items. Once the items were developed, the scales were evaluated by a team of six researchers to assess the content validity of the items by ensuring that they were 
adequately reflective of the engagement sub-dimensions (Step 3). These researchers were from the disciplines of psychology, management, and information systems. Each had prior experience in engagement research. The feedback from the team led to adjustments to some of the items to ensure that they were clearly worded.

Next, a series of data collection efforts were conducted through Amazon's Mechanical Turk (MTurk). MTurk was deemed appropriate for this study, as previous research has shown that it is a feasible and costeffective way to gather psychometrically valid and reliable data [e.g., 4]. In the first round of data collection, 133 individuals were recruited from MTurk to watch a brief 2-minute video and complete a survey with the engagement items (Steps $4 \& 5$ ). Based on the results and the resulting adjustment to the scale, a second round of data was collected from a sample of 120 MTurk workers using the same task. The scale was further refined and a third sample of data was collected from 120 MTurk workers using the same task as the previous two times (Steps 6 \& 7). Then, a fourth sample of data was collected with 115 individuals being recruited from MTurk to complete the same task and survey items, which validated the resulting 13-item engagement scale (Step 8).

We next aimed to cross-validate the tool with a fifth sample, which consisted of workplace employees (Step 9). To do so, we first adapted the engagement scale items in order to ensure that they assessed workplace engagement. Then, we recruited a sample of 144 U.S. employees through MTurk. Each participant worked an average of at least 20 hours per week (note that hours dedicated to MTurk employment were excluded).

\section{Results}

Exploratory factor analysis (EFA) was conducted on the first round of data collected to assess the loadings of each item and to empirically derive the factor structure of the data (Steps 4 and 5). Upon inspection of the eigenvalues and scree plot, it was found that three factors explained most of the variance. Specifically, these factors explained $58 \%$ of the total variance, with factor 1 explaining $33 \%$, factor 2 explaining $18 \%$, and factor 3 explaining 7\%. Only items that significantly loaded onto a primary factor and did not significantly load onto a second factor were retained (Step 6). Further, additional items were developed to assess engagement. Overall, this resulted in seven items to measure cognitive engagement, eight items to measure emotional engagement, and eight items to measure behavioral engagement.

In order to be able to assess the properties of the new items, a second round of data was collected (Step 7). An EFA was run on the second dataset to examine the new item properties (Step 6). As before, three factors explained most of the variance. Specifically, these factors explained $58 \%$ of the total variance, with factor 1 explaining $42 \%$, factor 2 explaining $10 \%$, and factor 3 explaining $6 \%$. The pool of items was again refined based significant loadings and cross-loadings. Further, the construct definition of cognitive engagement was reassessed, which led to the creation of six new items.

Consequently, a third sample of data was collected (Step 7). An EFA was run on the third dataset, and as before, three factors explained most of the variance. Specifically, these factors explained $61 \%$ of the total variance, with factor 1 explaining $37 \%$, factor 2 explaining $16 \%$, and factor 3 explaining $8 \%$. Thirteen items (3 for emotional, 7 for behavioral, and 3 for cognitive) had significant primary loadings and no significant cross-loadings, and therefore were retained.

Next, a fourth sample of data was collected, and confirmatory factor analyses (CFA) were run to validate the factor structure of the 13-item engagement scale (Step 8). Specifically, a CFA was conducted with all items that were retained from the previous step. This model (i.e., Model 1) demonstrated good fit (SB- $\chi^{2}(74)$ $=155.67, p<.05, \mathrm{CFI}=.93, \mathrm{TLI}=.92, \mathrm{SRMR}=.08$, RMSEA=.08). Cronbach's alpha for cognitive, behavioral, and emotional subscales were $.73, .94$, and .86 , respectively. It was found that one cognitive engagement item (i.e., "I re-checked my responses after answering the quiz questions") was negatively influencing Cronbach's alpha, and therefore was removed. The removal of this item increased the Cronbach's alpha for the cognitive engagement subscale to .79 . The CFA was then re-run to assess final model fit. The resulting model also had a good fit $\left(\mathrm{SB}-\chi^{2}(78)=\right.$ 138.87, $p<.05, \mathrm{CFI}=.94, \mathrm{TLI}=.92$, $\mathrm{SRMR}=.07$, RMSEA $=.08)$. Additionally, this model fit significantly better than the first $\left(\Delta \mathrm{SB}-\chi^{2}(4)=16.8, p<.01\right)$.

Finally, a fifth sample was collected, this time consisting of workplace employees (Step 9). For this data collection effort, the engagement scale was adapted for workplace engagement. Next, a CFA was run to ensure that the same factor structure held in this new sample. This model demonstrated excellent fit (SB$\chi^{2}(62)=123.16, p<.05, \mathrm{CFI}=.96, \mathrm{TLI}=.95, \mathrm{SRMR}=.06$, RMSEA=.06), with standardized item loadings ranging from 0.54 to 0.89 . The correlation between the emotional and behavioral scales was .30 , between the emotional and cognitive scales was .52, and between the cognitive and behavioral scales was .74. Cronbach's alpha for the cognitive, behavioral, and emotional subscales were $.73, .92$, and .86 , respectively.

See Tables 1 and 2 for the final engagement scale items in both contexts. 
Table 1. Final Items with Factor Loadings

\begin{tabular}{|c|c|c|c|}
\hline Item & Cognitive & Behavioral & Emotional \\
\hline I asked myself questions to check if I understood the contents of the video* & 0.52 & & \\
\hline I had a learning goal prior to watching this video & 0.79 & & \\
\hline Watching this video met some of my learning goals & 0.98 & & \\
\hline I listened to the contents of the video as I was expected to & & 0.74 & \\
\hline I made an effort to watch the video in its entirety & & 0.81 & \\
\hline I dutifully followed the instructions for this activity & & 0.86 & \\
\hline I was being attentive to what was being said in the video & & 0.85 & \\
\hline I was actively involved in watching the video & & 0.78 & \\
\hline I diligently watched the video & & 0.91 & \\
\hline I was dutifully paying attention to this video & & 0.85 & \\
\hline It made me happy to watch this video & & & .83 \\
\hline I care about the contents of this video & & & .70 \\
\hline This video had a positive impact on my mood & & & .92 \\
\hline
\end{tabular}

*Italicized text may be replaced when using scale in other contexts and domains.

Table 2. Workplace Version with Factor Loadings

\begin{tabular}{|c|c|c|c|}
\hline Item & Cognitive & Behavioral & Emotional \\
\hline I ask myself questions to check if I understand how to complete my job tasks & 0.65 & & \\
\hline I set goals for myself prior to completing my job tasks & 0.54 & & \\
\hline Completing my job tasks results in some of my goals being met & 0.84 & & \\
\hline I do my job as I am expected to & & 0.60 & \\
\hline I make an effort to fully complete my job tasks & & 0.72 & \\
\hline I dutifully follow the instructions for my job & & 0.83 & \\
\hline I am attentive to my job & & 0.85 & \\
\hline I am actively involved in my job & & 0.82 & \\
\hline I diligently complete my job tasks & & 0.84 & \\
\hline I dutifully pay attention to my job tasks & & 0.81 & \\
\hline My job makes me happy & & & .89 \\
\hline I care about my job & & & .74 \\
\hline My job has a positive impact on my mood & & & .83 \\
\hline
\end{tabular}

\section{Discussion \& Conclusions}

Engagement is recognized as a critical phenomenon of interest in a variety of disciplines and application domains. However, the existing measures of engagement are typically specific to the domain in which the research is conducted. The aim of our research is to build on the synergies of the various disciplines in which engagement has been studied and propose a discipline-independent definition of engagement and measurement scale. Accordingly, we first distinguished between three temporal levels of engagement in terms of the expected length of the engagement (task/activity, initiative, and continuous). We further explored the differences in the conceptualization of engagement, viz. affective, behavioral, and cognitive in two different contexts (learning and workplace). We then offered a comprehensive definition of engagement that accommodates the differences between three conceptual engagement types. Finally, based on this definition, we developed a measurement scale that can be used across domains and contexts. We iteratively refined the items in this scale through a series of five data samples to arrive at the final scale. Our results provide preliminary evidence for the scale's validity in two domains (online learning and work engagement).

\subsection{Implications for research and practice}

Our findings have several implications for research. First, we propose a definition and conceptualization of engagement that aims to be applicable across domains and disciplines. As such, it lays an initial foundation for theory development to identify antecedents to engagement and to design specific technological or procedure-based interventions to improve engagement. It further grounds research where engagement is an antecedent to other phenomena of interest, such as quality of learning, intention to continue to use a website, participate in an initiative, or commitment to an organizational entity. Also, our three-part definition of engagement and three-level temporal perspective on engagement provide a $3 \times 3$ matrix of different forms of engagement. This will increase the specificity with which researchers can report on their engagement studies and make it easier to compare and contrast 
empirical findings across studies. Second, to the best of our knowledge, our measurement scale is the first instrument that has the potential to be applied across domains and contexts, with only a minor adjustment to the items to refer to the activity or domain under consideration. This will support engagement researchers and increase the comparability of research findings.

The distinction between different temporal and conceptual types of engagement will allow developers of technologies, activities, and other objects of engagement to more precisely target which form of engagement they aim to improve. Further, the modest length of the engagement measurement scale makes it practically useful for developers and researchers to apply.

\subsection{Limitations \& Future research}

There are a number of limitations that have to be addressed in future research efforts. First, the number of items for the cognitive and emotional part of the engagement scale is limited. It would be useful to expand these sets of items to increase the instruments robustness. Second, we also plan to finish the instrument development procedure in terms of cross-validating the scale with samples from different populations and developing scale norms. Although we gathered data from a rich collection of samples, further validation of the final version of the instrument is required across contexts and across each of the three temporal engagement levels. We also need to gather evidence for predictive validity and build the nomological network of constructs linked to engagement. Finally, we intend to apply the instrument in a situation where it is known that engagement levels will differ based on certain interventions, and then demonstrate that the instrument indeed measures this correctly.

For future research, we also plan to use the instrument to investigate the relationship between the three forms of engagement. It would be useful to explore under which circumstances a higher level of one form of engagement goes hand in hand with lower levels for other forms. For example, when subjects participate in an online activity experience high levels of cognitive engagement, they may be so absorbed in the activity that they do not display high levels of behavioral engagement. Finally, engagement can also be measured from a physiological perspective. It would be worthwhile to determine which physiological measures (e.g. facial expressions, eye gazes, and pupil dilation) correlate to elevated levels of affective, behavioral, and cognitive engagement.

In this paper we provide a general three-component definition of engagement that is applicable to a wide range of activities and domains. We also report our initial efforts to develop a three-subscale engagement inventory that can be utilized, with minor item adjustment, in a wide variety of settings. In doing this, we have taken steps to integrate a very scattered engagement literature that for the most part has developed independently across disciplines.

\section{References}

[1] B. A. Apenes Solem. "Influences of customer participation and customer brand engagement on brand loyalty." Journal of Consumer Marketing, 33 (2016), pp. 332-342.

[2] I. Archambault, M. Janosz, J. Morizot, and L. Pagani. "Adolescent behavioral, affective, and cognitive engagement in school: Relationship to dropout." Journal of School Health, 79 (2009), pp. 408-415.

[3] C. Bailey, A. Madden, K. Alfes, and L. Fletcher. "The meaning, antecedents and outcomes of employee engagement: A narrative synthesis." International Journal of Management Reviews, 19 (2017), pp. 31-53.

[4] M. Buhrmester, T. Kwang, and S. D. Gosling. "Amazon's Mechanical Turk: A new source of inexpensive, yet high-quality, data?." Perspectives on Psychological Science, 6 (2011), pp. 3-5.

[5] B. J. Calder, E. C. Malthouse, and U. Schaedel. "An experimental study of the relationship between online engagement and advertising effectiveness." Journal of Interactive Marketing, 23 (2009), pp. 321-331.

[6] P. Chapman. "Models of engagement: Intrinsically motivated interaction with multimedia learning software." $\mathrm{PhD}$ dissertation, University of Waterloo, 1997.

[7] H. Coates. "The value of student engagement for higher education quality assurance." Quality in Higher Education, 11 (2005), pp. 25-36.

[8] J. P. Connell and J. G. Wellborn, Competence, autonomy, and relatedness: A motivational analysis of self-system processes, (1991) in $\mathrm{M}$. Gunnar and A. Stroufe, A., eds., Minnesota Symposium on Child Psychology, Lawrence Erlbaum Associates, Inc., Hillsdale, 1991, pp. 4377.

[9] M. Csikszentmihalyi, The Psychology of Optimal Performance, Harper \& Row, New York, 1990.

[10]M. Czarnowsky, Learning's Role in Employee Engagement: An ASTD Research Study, American Society for Training and Development, Alexandria, VA, 2008.

[11] Economist Intelligence Unit (EIU) (2007a), "Beyond loyalty: meeting the challenge of 
customer engagement, part 1", available at: www.adobe.com/engagement/pdfs/partI.pdf

[12] J. D. Finn, "Withdrawing from school", Review of Educational Research, 59 (1989), pp. 117-142.

[13] J. D. Finn, School Engagement \& Students at Risk, National Center for Educational Statistics, Washington, D.C., 1993.

[14]J. D. Finn and D. A. Rock, "Academic success among students at risk for school failure", Journal of Applied Psychology, 82 (1997), pp. 221.

[15] J. A. Fredricks, P. C. Blumenfeld, and A. H. Paris. "School engagement: Potential of the concept, state of the evidence", Review of Educational Research 74 (2004), pp. 59-109.

[16]J. A. Fredricks and W. McColskey, The measurement of student engagement: $A$ comparative analysis of various methods and student self-report instruments, in S. Christenson, A. Reschly, and C. Wylie eds., Handbook of research on student engagement, Springer, Boston, 2012, pp. 763-782.

[17] J. A. Fredricks, P. Blumenfeld, J. Friedel, and A. Paris, School engagement, In K. A. Moore and L. H. Lippman, eds., What do children need to flourish?, Springer, Boston, 2005, pp. 305-321.

[18]B. A. Greene, "Measuring cognitive engagement with self-report scales: Reflections from over 20 years of research", Educational Psychologist, 50 (2015), pp. 14-30.

[19]A. Gregory, J. P. Allen, A. Y. Mikami, C. A. Hafen, and R. C. Pianta, "Effects of a professional development program on behavioral engagement of students in middle and high school", Psychology in the Schools, 51 (2014), pp. 143-163.

[20]M. A. Griffin, S. K. Parker, and A. Neal, "Is behavioral engagement a distinct and useful construct?", Industrial and Organizational Psychology, 1 (2008), pp. 48-51.

[21] J. K. Harter, F. L. Schmidt, and T. L. Hayes, "Business-unit-level relationship between employee satisfaction, employee engagement, and business outcomes: a meta-analysis", Journal of Applied Psychology, 87 (2002): 268.

[22] C. R. Henrie, L. R. Halverson, and C. R. Graham, "Measuring student engagement in technologymediated learning: A review", Computers \& Education, 90 (2015), pp. 36-53.

[23] V. T. Ho, S. S. Wong, and C. H. Lee. "A tale of passion: Linking job passion and cognitive engagement to employee work performance." Journal of Management Studies, 48 (2011), pp. 26-47.

[24] N. Iten and D. Petko, "Learning with serious games: Is fun playing the game a predictor of learning success?", British Journal of Educational Technology, 47 (2016), pp. 151-163.

[25] S. R. Jimerson, E. Campos, and J. L. Greif, "Toward an understanding of definitions and measures of school engagement and related terms", The California School Psychologist, 8 (2003), pp. 7-27.

[26] W. A. Kahn, "Psychological conditions of personal engagement and disengagement at work", Academy of Management Journal, 33 (1990), pp. 692-724.

[27]W. A. Kahn, "To be fully there: Psychological presence at work", Human Relations, 45 (1992), pp. 321-349.

[28]A. King, "From sage on the stage to guide on the side", College Teaching, 41 (1993), pp. 30-35.

[29] S. Langelaan, A. B. Bakker, L. J. Van Doornen, and W. B. Schaufeli, "Burnout and work engagement: Do individual differences make a difference?", Personality and Individual Differences, 40 (2006), pp. 521-532.

[30] S. Langelaan, A. B. Bakker, L. J. Van Doornen, and W. B. Schaufeli, "Burnout and work engagement: Do individual differences make a difference?", Personality and Individual Differences, 40 (2006), pp. 521-532.

[31] Laurel, B. (1993). Computers as Theatre. Reading, MA: Addison-Wesley.

[32] E. A. Linnenbrink and P. R. Pintrich, "The role of self-efficacy beliefs instudent engagement and learning in the classroom", Reading \& Writing Quarterly, 19 (2003), pp. 119-137.

[33]B. Little and P. Little, "Employee engagement: Conceptual issues", Journal of Organizational Culture, Communications and Conflict, 10 (2006): 111.

[34] W. H. Macey and B. Schneider, "The meaning of employee engagement", Industrial and Organizational Psychology, 1 (2008), pp. 3-30.

[35] S. B. MacKenzie, P. M. Podsakoff, and N. P. Podsakoff, "Construct measurement and validation procedures in MIS and behavioral research: Integrating new and existing techniques", MIS Quarterly, 35 (2011), pp. 293-334.

[36] H. M. Marks, "Student engagement in instructional activity: Patterns in the elementary, middle, and high school years", American Educational Research Journal, 37 (2000), pp. 153-184.

[37]C. Maslach, M. P. Leiter, and W. Schaufeli, Measuring burnout, in S. Cartwright and C. L. Cooper, eds., The Oxford handbook of organizational well being, Oxford University Press, Oxford, 2008, pp. 86-108.

[38] D. R. May, R. L. Gilson, and L. M. Harter, "The psychological conditions of meaningfulness, safety and availability and the engagement of the human 
spirit at work", Journal of Occupational and Organizational Psychology, 77 (2004), pp. 11-37.

[39]A. Mollen and H. Wilson, "Engagement, telepresence and interactivity in online consumer experience: Reconciling scholastic and managerial perspectives", Journal of Business Research, 63 (2010), pp. 919-925.

[40] National Center for School Engagement (NCSE). Retrieved February 19, 2017, from http://www.schoolengagement.org. [41] D. Newman and D. A. Harrison, "Been there, bottled that: Are state and behavioral work engagement new and useful construct "wines"?", Industrial and Organizational Psychology, 1 (2008), pp. 31-35.

[41]P. M. Newmann,G. G. Wehlage, \& S. D. Lamborn, The significance and sources of student engagement, in F. M. Newmann, ed., Student engagement and achievement in American secondary schools, Teachers College Press, New York, 1992, pp. 11 -39.

[42] Pintrich, P., and D. Schunk, Motivation in Education: Theory, Research \& Applications, Prentice-Hall, Englewood Cliffs, 1996.

[43] W. Quesenbery, The five dimensions of usability, In M. J. Albers and M. B. Mazur, eds., Content and complexity, Routledge, New York, 2014, pp. 93114.

[44]L. Rhoades, R. Eisenberger, and S. Armeli, "Affective commitment to the organization: The contribution of perceived organizational support", Journal of Applied Psychology, 86 (2001), pp. 825.

[45]B. L. Rich, J. A. Lepine, and E. R. Crawford, "Job engagement: Antecedents and effects on job performance", Academy of Management Journal, 53 (2010), pp. 617-635.

[46]J. I. Rotgans and H. G. Schmidt, "Situational interest and academic achievement in the activelearning classroom", Learning and Instruction, 21 (2011), pp. 58-67.

[47]N. P. Rothbard, "Enriching or depleting? The dynamics of engagement in work and family roles", Administrative Science Quarterly, 46 (2001), pp. 655-684.

[48] A. M. Saks, "Antecedents and consequences of employee engagement", Journal of Managerial Psychology, 21 (2006), pp. 600-619.

[49]A. M. Saks, "The meaning and bleeding of employee engagement: How muddy is the water", Industrial and Organizational Psychology, 1 (2008), pp. 40-43.

[50] C. M. Sashi, "Customer engagement, buyer-seller relationships, and social media", Management Decision, 50 (2012), pp. 253-272.

[51] W. B., Schaufeli, A. B. Bakker, and M. Salanova, "The measurement of work engagement with a short questionnaire: A cross-national study", Educational and Psychological Measurement, 66 (2006), pp. 701-716.

[52] W. B., Schaufeli, M. Salanova, V. González-Romá, and A. B. Bakker, "The measurement of engagement and burnout: A two sample confirmatory factor analytic approach", Journal of Happiness Studies, 3 (2002), pp. 71-92.

[53] V. Shankar, M. Kleijnen, S. Ramanathan, R. Rizley, S. Holland, and S. Morrissey, "Mobile shopper marketing: Key issues, current insights, and future research avenues", Journal of Interactive Marketing, 34 (2016), pp. 37-48.

[54]B. Shuck and T. G. Reio Jr, "The employee engagement landscape and HRD: How do we link theory and scholarship to current practice?", Advances in Developing Human Resources, 13 (2011), pp. 419-428.

[55] E. A. Skinner, T. A. Kindermann, and C. J. Furrer, "A motivational perspective on engagement and disaffection: Conceptualization and assessment of children's behavioral and emotional participation in academic activities in the classroom", Educational and Psychological Measurement, 69 (2009). pp. 493-525.

[56] S. Sonnentag, "Recovery, work engagement, and proactive behavior: a new look at the interface between nonwork and work", Journal of Applied Psychology, 88 (2003), pp. 518.

[57] J. Van Doorn, K. N. Lemon, V. Mittal, S. Nass, D. Pick, P. Pirner, and P. C. Verhoef, "Customer engagement behavior: Theoretical foundations and research directions", Journal of Service Research, 13 (2010), pp. 253-266.

[58]J. D. Willms, Monitoring School Performance: A Guide for Educators, Routledge, Washington, D.C., 2003.

[59]D. Zyngier, "(Re) conceptualising student engagement: Doing education not doing time", Teaching and Teacher Education, 24 (2008), pp. 1765-1776. 